\title{
Surgical outcomes of infectious spondylitis after vertebroplasty, and comparisons between pyogenic and tuberculosis
}

\author{
Jen-Chung Liao*, Po-Liang Lai, Lih-Hui Chen and Chi-Chien Niu
}

\begin{abstract}
Background: Infection after vertebroplasty (VP) is a rare but serious complication. Previous literatures showed most pathogens for infection after VP were bacteria; tuberculosis (TB) induced infection after VP was extremely rare. We reported our treatment experiences of cases with infectious spondylitis after VP, and compared the differences between developed pyogenic and TB spondylitis.

Methods: From January 2001 to December 2015, 5749 patients had undergone VP at our department were reviewed retrospectively. The causative organisms were obtained from tissue culture of revision surgery. Parameters including type of surgery, the interval between VP and revision surgery, neurologic status, and visual analog scale (VAS) of back pain were recorded. Laboratory data at the time of VP and revision surgery were collected. Charlson comorbidity index $(\mathrm{CCl})$, preoperative bacteremia, urinary tract infection (UTI), pulmonary TB history were also analyzed.

Results: Eighteen patients were confirmed with developed infectious spondylitis after VP (0.32\%, 18/5749). Two were male and 16 were female. The median age at VP was 73.4 years. Nine patients were TB and the other nine patients were pyogenic. The interval between VP and revision surgery ranged from 7 to 1140 days (mean 123.2 days). The most common type of revision surgery was anterior combined with posterior surgery. Seven patients developed neurologic deficit before revision surgery. Three patients died within 6 months after revision surgery, with a mortality of 16.7\%. Finally, VAS of back pain was improved from 7.4 to 3.1. Seven patients could walk normally, the other 8 patients had some degree of disability. Both pyogenic and TB group had similar age, sex, and CCI distribution. The interval between VP and revision surgery was shorter in the patients with pyogenic organisms (75.9 vs 170.6 days). At revision surgery, WBC and CRP were prominently elevated in the pyogenic group. Five in the pyogenic group had UTI and bacteremia; five in TB group had a history of lung TB.
\end{abstract}

Conclusions: Infection spondylitis after VP required major surgery for salvage with a relevant part of residual disability. Before VP, any bacteremia/UTI or history of pulmonary TB should be reviewed rigorously; any elevation of infection parameters should be scrutinized strictly.

Keywords: Vertebroplasty, Infection, Pyogenic, Tuberculosis, Surgery

\footnotetext{
* Correspondence: jcl1265@adm.cgmh.org.tw

Department of Orthopedics Surgery, Bone and Joint Research Center, Chang

Gung Memorial Hospital, Chang Gung University, No.5, Fu-Shin Street

Kweishian, Taoyuan 333, Taiwan
}

(c) The Author(s). 2018 Open Access This article is distributed under the terms of the Creative Commons Attribution 4.0 International License (http://creativecommons.org/licenses/by/4.0/), which permits unrestricted use, distribution, and reproduction in any medium, provided you give appropriate credit to the original author(s) and the source, provide a link to the Creative Commons license, and indicate if changes were made. The Creative Commons Public Domain Dedication waiver (http://creativecommons.org/publicdomain/zero/1.0/) applies to the data made available in this article, unless otherwise stated. 


\section{Background}

Since Galibert et al. first demonstrated percutaneous vertebroplasty (VP) for the treatment of haemangioma of the spine in 1987 [1], VP has been generally accepted for the surgical treatment of compression fractures in thoracic or lumbar vertebrae. Reported acute symptomatic complications associated with VP are low: usually $1 \%$ for osteoporotic fractures, and up to $10 \%$ for metastatic lesion [2,3]. Although the incidence is very low, infection might indeed occur after VP. Infectious spondylitis after VP is serious, and might lead to neurological deficit and even death. Most infectious pathogens found after vertebroplasty were bacterial; but the largest series studying spinal infection after vertebroplasty or kyphoplasty contained only nine patients [4]. Tuberculosis (TB) after VP is rare; these cases are reported sporadically in the literature [5-10]. There is no literature discussing the differences between pyogenic and $\mathrm{TB}$ infection after VP. In this study, we report our experiences in managing patients with infectious spondylitis after VP. The pathogens of these patients included various bacteria or TB. We use their clinical history, laboratory data, and surgical outcomes to uncover differences between pyogenic and TB infectious spondylitis after VP.

\section{Methods}

After obtaining approval from the Institute of Review Board, we retrospectively reviewed patients who had undergone VP in our department for osteoporotic compression fractures between January 2001 and December 2015. The only criteria for enrolment was that causative organisms for infectious spondylitis after VP must be obtained from tissue culture in revision surgery. Patients were categorized into two groups according to the pathogens of their infection after VP: a pyogenic and a TB group. Demographic data was collected from medical records, including age, sex, the number and level of VP, interval between $\mathrm{VP}$ and revision surgery, and type of revision surgery. Laboratory data focused on inflammatory parameters including the $\mathrm{WBC}, \mathrm{ESR}$, and CRP recorded at the time of VP and revision surgery. The medical condition of these patients was evaluated using the weighted Charlson Comorbidity Index (CCI) [11]. Neurologic status just before revision surgery was determined using the American Spinal Injury Association (ASIA) impairment scale. Back pain status was recorded using the Visual Analogue Scale (VAS) at revision surgery, and final follow up was recorded. We determined final clinical outcomes through ambulation, with four grades: normal ambulation without support, ambulation with crutches or walker support, ambulation in a wheelchair, or unable to ambulate. We especially focused on the incidence of risk factors that might induce the development of infectious spondylitis after VP. These risk factors included urinary tract infection (UTI), any episode of bacteraemia within the 3 months before VP, any episode of organ infection by bacteria or TB within the 3 months before VP, or a history of pulmonary TB.

\section{Results}

Five thousand seven hundred forty nine patients underwent VP in our department in the period of our study. Totally twenty-three patients underwent revision surgeries because they were suspected to have infectious spondylitis after VP by clinical symptoms, laboratory data and radiographic finding; the indications for these 23 patients were intractable back pain with or without neurologic deficit. Eighteen patients were enrolled in to study because they were confirmed to have developed infectious spondylitis at the level of VP according to positive culture data from the revision surgery, the other 5 patients were excluded. The positive culture rate was $78 \%(18 / 23)$ in revision surgeries. The incidence of infectious spondylitis after VP was $0.32 \%(18 / 5749)$ by positive tissue culture. There were 24 vertebrae (10 in thoracic spine and 14 in lumbar spine) involved by infection in these 18 patients. Nine patients had bacterial infection and the other nine patients were confirmed with TB infection. The average age of the 18 patients at the time of VP was 73.4 years (63 to 90) and the mean CCI was 1.7 ( 0 to 4 ); the mean interval between $\mathrm{VP}$ and revision surgery was 123 days (7 to 1140). The average $\mathrm{WBC}$ was within normal range at the time of $\mathrm{VP}$ and revision surgery, but CRP and ESR were elevated in most patients, especially at the time of revision surgery. Six patients developed neurologic deficits before revision surgery (one with ASIA B, two with ASIA C, and three with ASIA C). Three patients had treatment with only posterior decompression and instrumentation surgeries, four patients underwent anterior debridement and fusion surgeries, and the other 11 patients underwent combined anterior and posterior surgeries. Just before revision surgery, VAS of back pain was high, at 7.0 points (5 to 9), and eventually improved to 2.7 points (1 to 6). By the final follow up, three patients had died due to surgical and infectious complications; two patients needed wheelchairs for ambulation, four patients could ambulate with the support of walkers, and the other nine patients ambulated normally without any support. The demographic, laboratory, and clinical data of these 18 patients is listed in Table 1.

\section{The TB group (nine cases)}

Eight female and one male patients were enrolled in this group, with a mean age of 75.1 years (66 to 90). Co-morbidities were found in eight of the nine patients, with an average of 1.2 point of CCI. Five patients had a history of pulmonary tuberculosis. 


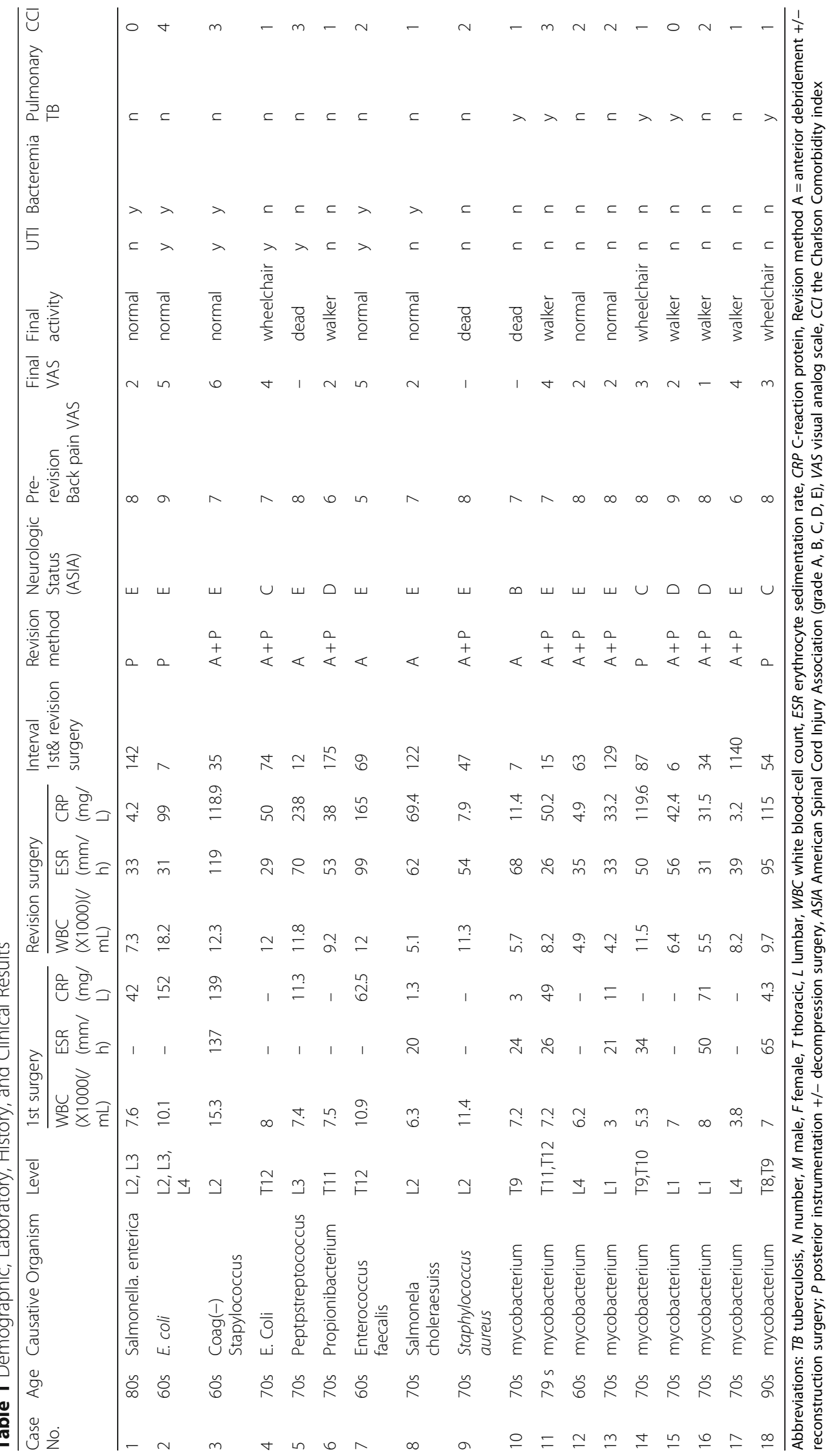


Before VP, WBC counts were all within the normal range; CRP was elevated in only two patients, and was within normal ranges or not checked for the other seven. Before revision surgery, the WBC counts of most patients were slightly elevated, but still within normal range, however the CRP data of seven patients was elevated above the normal limit, with an average of 57.6. The interval between VP and revision surgery ranged from 5 to 1125 days, with a mean of 250 days. At revision surgery, seven patients underwent anterior debridement and reconstruction surgery, six of whom also received posterior instrumentation for augmentation; two patients received posterior only surgeries with decompression, fusion and instrumentation. At the end of follow-up, one patient with paraplegia had passed away, two were in wheelchairs, four patients required a walker, and two had improved functionally and could walk unassisted. Figure 1 showed a case with TB spondylitis after VP. Briefly, a patient with L1 compression fracture after a falling accident underwent VP; L1 spondylitis was diagnosed 4 months later due to back pain again. Combined anterior and posterior surgery was performed, and TB-PCR and culture obtained during the operation were positive.

\section{The pyogenic group (nine cases)}

There were also nine cases in the pyogenic group, including one male and eight females, with a mean age of 71.8 years at the time of VP. Eight patients in this group had underlying disease, with an average CCI of 1.9 in these nine patients. WBC counts were still within normal range $(9400 / \mathrm{ml})$ just before VP, but reached the upper limit; six cases had CRP, with an average of $68.0 \mathrm{mg} / \mathrm{L}$. The interval between $\mathrm{VP}$ and revision surgery ranged from 7 to 175 days, with a mean of 75.9 days. At the time of revision surgery, the neurologic status of seven patients was intact, two had some degree of neurologic deficit. The mean VAS of back pain was 7.2 points. Three patients received revision surgery by anterior approach only with debridement and fusion; two cases had posterior only surgery with decompression and instrumentation; the other four underwent salvage surgeries using combined anterior and posterior procedures. The causative organisms were various, included E. coli, Salmonella enterica, Salmonella choleraesuis, Staphylococcus aureus, Coag(-) Staphylococcus, Peptostreptococcus, Propionibacterium, and Enterococcus faecalis. Two patients died, one needed a wheelchair and one patient required a walker for ambulation. The other five

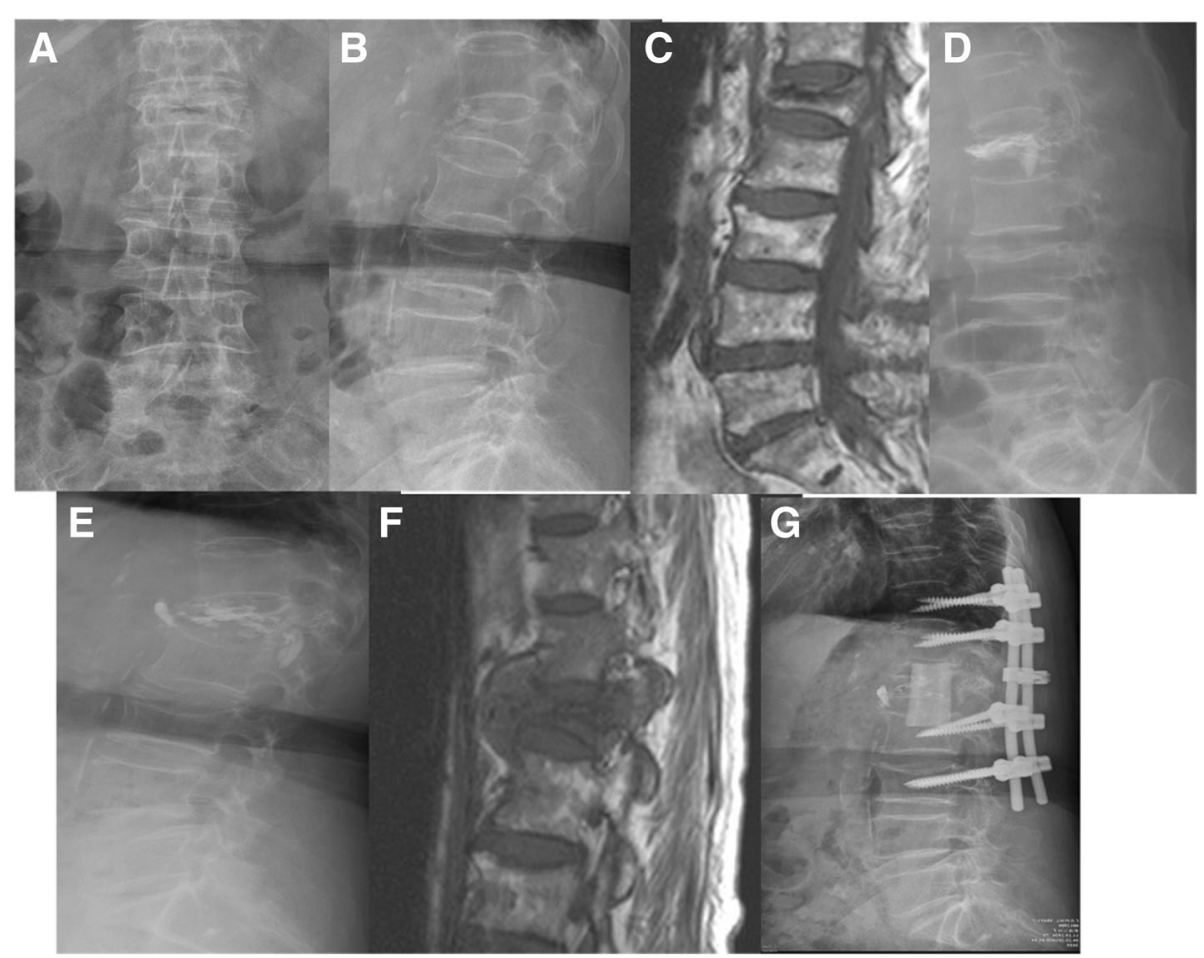

Fig. $1 \mathrm{~A}$ case represented tuberculosis infection after vertebroplasty (VP). Initial radiographic images and MRI revealed L1 compression fracture $(\mathbf{a}, \mathbf{b}, \mathbf{c})$. This patient received L1 VP first $(\mathbf{d})$. After VP, back pain was subsided dramatically, however, severe low back pain without neurologic deficits was appeared again four months later. Plain radiograph showed L1 body collapse with cement breakage (e). MRI revealed L1 spondylitis with abscess formation (f). Reconstruction revision surgery was performed for this patient (g). Tissue culture showed mycobacterium tuberculosis 
improved functionally and could walk unassisted. The average VAS in the survival patients improved to 2.9. Figure 2 demonstrated a case with pyogenic infectious spondylitis after VP.

\section{Pyogenic versus TB}

Both groups had similar age, sex, and CCI distribution. Preoperative neurologic status and VAS scale before revision surgery was also equal. The interval between VP and revision surgery was shorter in the patients with pyogenic organisms (75.9 vs 170.6 days). At revision surgery, WBC and CRP were higher elevated in the pyogenic group. Two in pyogenic group and one in TB group died because of complications by revision surgeries. Final surgical outcomes including VAS and activity in those survivors were similar in both group. Table 2 illustrated comparisons between pyogenic and TB group.

\section{Discussion}

The percutaneous transpedicular injection of cement into a vertebral body is a very minor procedure, but still carries a risk of developing postoperative infection. The reported incidence of infection after VP or KP is between 0 and $1 \%[12,13]$. In our study, with the largest study population of similar studies, the incidence was $0.32 \%$, which was similar to that reported by Abdelrahman et al. (0.46\%) [4].

Most bacteria or TB in this study were low-virulence organisms. We believe that these organisms already existed in the patients, and the infection process was triggered by the cement injection procedure, leading to the consequential results. Yu et al. described the first case of pyogenic spondylitis after VP, for a patient who had an episode of urinary tract infection just 1 week before VP [14]. Other infection sources, including cholecystitis, meningitis, or post-laminectomy wound infection, were thought to be associated with pyogenic spondylitis after VP $[15,16]$. Under very rare conditions, even skin acne can cause post-VP spondylitis [17]. The first TB spondylitis after VP was reported in 2006; the authors suggested that the possible mechanism leading to the development of $\mathrm{TB}$ infection after VP was the release of mycobacteria from macrophages containing quiescent bacilli which migrated to the vertebrae of the VP. Ivo et al. and Kang et al. reported that cases with TB spondylitis after VP all had a pulmonary TB history $[7,9]$. There were also five patients in the TB group of our study who had pulmonary TB when they were young. This suggests that TB bacilli could exist inside the body even after the completion of a course of

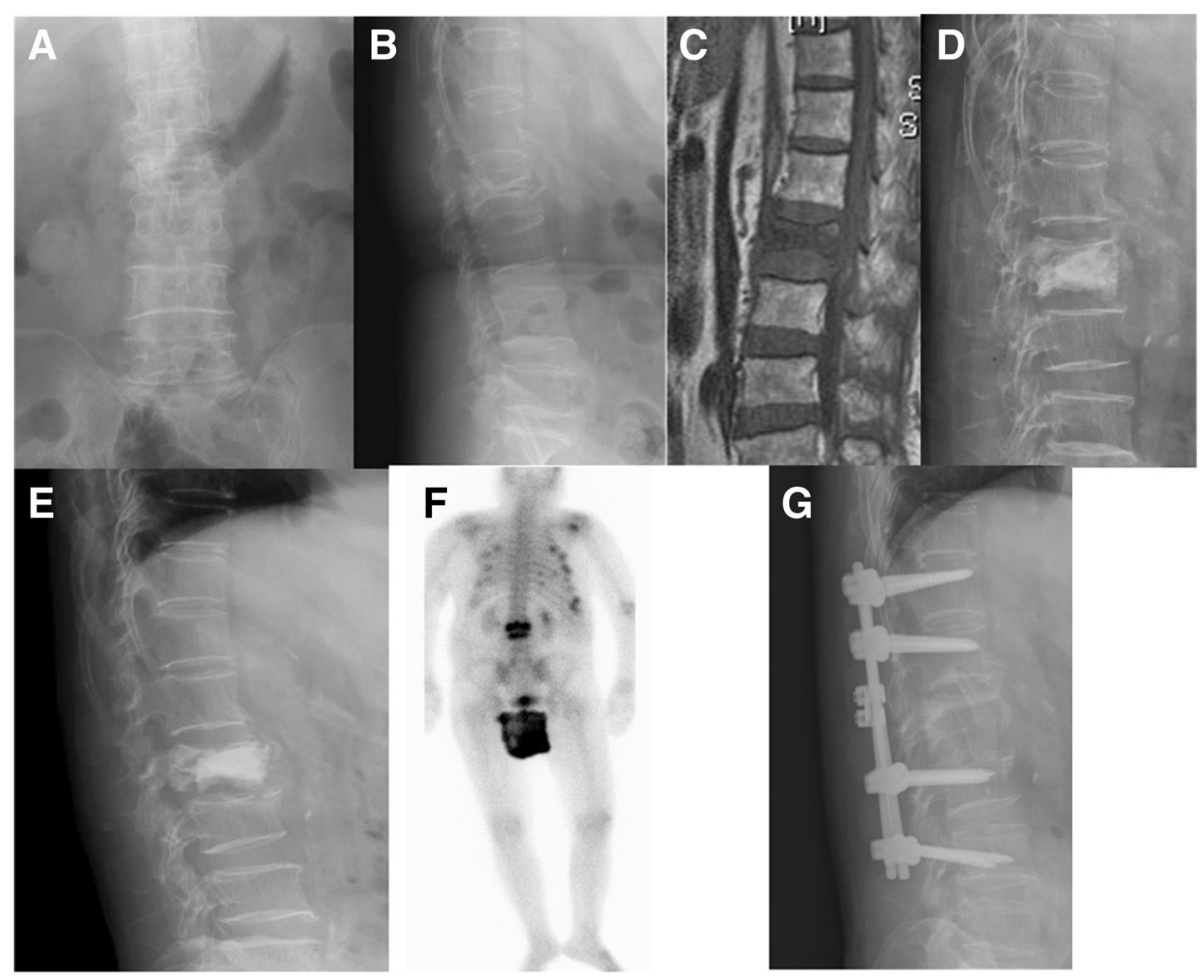

Fig. 2 A case represented pyogenic spondylitis after VP. Initial radiographic images and MRI revealed L2 compression fracture (a, b, c). L2 VP was performed first (d). Svere low back pain was appeared again one month later. Plain radiograph showed L2 collapse with L2 lower endplate erosion (e). Gallium scan revealed L2-3 infectious spondylitis (f). Reconstruction revision surgery was performed (g). Tissue culture showed Coag (-) Staphylococcus 
Table 2 Comparisons between pyogenic and TB patients

\begin{tabular}{|c|c|c|}
\hline Characters & Pyogenic $(N=9)$ & $\mathrm{TB}(N=9)$ \\
\hline Age & 71.8 & 75.1 \\
\hline $\operatorname{Sex}(M: F)$ & $1: 8$ & $1: 8$ \\
\hline \multicolumn{3}{|l|}{ Level } \\
\hline T spine & 3 & 7 \\
\hline L spine & 9 & 5 \\
\hline \multicolumn{3}{|l|}{ 1st surgery } \\
\hline $\mathrm{WBC}(\mathrm{X} 1000)(/ \mathrm{mL})$ & 9.4 & 6.1 \\
\hline $\mathrm{ESR}(\mathrm{mm} / \mathrm{h})$ & Inadequate data & Inadequate data \\
\hline $\mathrm{CRP}(\mathrm{mg} / \mathrm{L})$ & Inadequate data & Inadequate data \\
\hline \multicolumn{3}{|l|}{ Revision surgery } \\
\hline WBC $(X 1000)(/ \mathrm{mL})$ & 11.0 & 7.1 \\
\hline $\operatorname{ESR}(\mathrm{mm} / \mathrm{h})$ & 61.1 & 48.1 \\
\hline CRP (mg/L) & 87.8 & 45.7 \\
\hline \multicolumn{3}{|l|}{ Revision method } \\
\hline A & 3 & 1 \\
\hline$P$ & 2 & 2 \\
\hline$A+P$ & 4 & 6 \\
\hline \multicolumn{3}{|c|}{ Neurologic Status (ASIA) } \\
\hline$E$ & 7 & 4 \\
\hline $\mathrm{D}$ & 1 & 2 \\
\hline$C$ & 1 & 2 \\
\hline B & 0 & 1 \\
\hline A & 0 & 0 \\
\hline Pre-revision VAS & 7.2 & 7.7 \\
\hline Final VAS & 3.1 & 2.6 \\
\hline \multicolumn{3}{|l|}{ Final activity } \\
\hline Normal & 5 & 2 \\
\hline Walker support & 1 & 4 \\
\hline On wheelchair & 1 & 2 \\
\hline Dead & 2 & 1 \\
\hline $\mathrm{CCl}$ & 1.9 & 1.4 \\
\hline
\end{tabular}

Abbreviations: $T B$ tuberculosis, $N$ number, $M$ male, $F$ female, $T$ thoracic, $L$ lumbar, WBC white blood-cell count, ESR erythrocyte sedimentation rate, CRP C-reaction protein, ASIA American Spinal Cord Injury Association, VAS visual analog scale, $\mathrm{CCl}$ the Charlson Comorbidity index

medicine, and VP procedure might cause these TB bacilli to seed around the cemented vertebrae, leading to infection.

In addition to previous bacteraemia from UTI or other internal organs, common skin pathogens might also induce vertebrae infection after VP. In the current study, one patient had a Staphylococcus aureus infection and one developed Propionibacterium species infection; these two pathogens can be seen in normal skin. Propionibacterium species are common gram positive anaerobic flora on the skin or inside acne, and Propionibacterium acnes is the most virulent. Propionibacterium species infection usually involves total joint arthroplasty, particularly in hip or shoulder arthroplasty [18, 19]. Profound spine infection induced by Propionibacterium species is extremely rare; but latent infection by this particular specie is related to developing lumbar disc degeneration or herniation [20]. Before this study, there was only one case report of vertebral osteomyelitis following VP induced by Propionibacterium species, and the authors emphasised the importance of prophylactic antibiotics, even with this minimally invasive procedure [17].

For spontaneous infectious spondylitis, there are many distinguishing finding in radiologic, clinical and laboratory features between pyogenic and TB. A patient with pyogenic spondylitis generally demonstrates more previous invasive spinal procedures, preceding bacteraemia, more episodes of fever, higher elevation of CRP and ESR, a higher percentage of WBC counts over $10,000 / \mathrm{mm} 3$ and a fraction of neutrophils $>75 \%$, and it is also more associated with chronic renal failure and liver cirrhosis. TB spondylitis is frequently associated with longer diagnostic delay, TB of other organs, more involvement of the thoracic spine, involvement of more spinal levels, and the presence of disc space sparing [21]. Similarly, in the present study, higher elevations of CRP, ESR and WBC counts were seen in the pyogenic group at the time of revision, however, there was more involvement of the thoracic spine, longer intervals between VP and revision surgery, and other organs affected by $\mathrm{TB}$ (lungs) were observed in the TB group.

Surgery is not always the initial treatment of choice for spontaneous infectious spondylitis. If the pathogenic organism is known, then conservative treatment with antibiotics or chemical agents for TB combined with motion restriction using a brace can be used to allowed recovery from infectious spondylitis. For those cases who have infectious spondylitis after VP, however, most of these patients will receive surgeries to relieve their intractable back pain, which is induced by unhealed fracture and infection; and some of these patients also has some degree of neurological impairment. The optimal surgical method for treating infection after VP was inconsistent in past literatures. Chen et al. demonstrated a case of pyogenic spondylitis after VP which could be successfully treated with percutaneous drainage followed by antibiotic-impregnated cement VP [22]. Laminectomy with pus drainage was successfully used to treat pyogenic or TB spine after VP, as reported by Soyuncu et al. [23]. Most spine surgeons reported in the literature advocated a combined anterior debridement/ fusion and posterior fixation for this kind of patient [4, $5,9,14,15,24,25]$. In the current study, most patients (10 out of $18,56 \%$ ) also received combined anterior and posterior procedures for their infectious spondylitis. 
Because their infection site was not only at the level of VP but also had some degree spreading to an adjacent disc space or vertebrae, anterior wide debridement and fusion with structured bone graft was the main method to achieve adequate decompression and reconstruction, and following posterior instrumentation could provide immediately strong stability and enhance anterior fusion.

The incidence of infectious spondylitis after VP was low and most previous literatures only had cases reports or a small case series in their articles [4-9, 14, 15, 17, 24, 25]. Park et al. reported experiences of 11 cases after VP or kyphoplasty and reviewed the other 42 cases in 26 published English articles on PubMed research [26]. According to the study from Park et al., there were three patients in their 11 cases (27\%) and 11 patients in the other 42 cases reviewed (26\%) had no organism in culture tissue; Staphylococcus aureus (10 cases, 19\%) and TB (10 cases, 19\%) were the most pathogen in these 53 cases. In the present study, five patients were excluded because there was no definite causative organism obtained at their revision surgery. If these five cases were included into the present study, the negative tissue culture rate was $22 \%(5 / 23)$, which was similar to the results of Park et al. However, the most pathogen in the present study was TB (9 cases), followed by Salmonella species ( 2 cases) and E coli ( 2 cases), the proportion of causative pathogen was different to that in Park's study. Most cases of post-VP pyogenic spondylitis developed days to months after VP and most cases of post-VP TB spondylitis happened months to years after VP, this scenario was similar in our and Park's study. In contrast to Park's study, we had no cases of post-VP TB spondylitis happened within days to weeks after initial VP, but there were two cases among Park's review; Park et al. thought the etiology of these two cases was pre-existed TB spondylitis and was misdiagnosed as simple osteoporosis compression fracture by theory of Chen et al [27].

\section{Conclusion}

Although VP is a minimally invasive procedure, the possibility of postoperative infection should not be ignored. Infectious spondylitis after VP generally requires major salvage surgery to overcome problems of infection, nerve compression, and spinal instability. TB spondylitis after VP takes longer to detect with a lower degree of elevation in infection parameters, but both kinds of infection might lead to some residual disability, even in complete treatment. In addition to standard skin preparation and the administration of prophylactic antibiotics, surgeons should preoperatively consider immune status, UTI or other infection source within 6 months, and history of pulmonary TB to prevent infection after VP.

\section{Abbreviations}

ASIA: American Spinal Injury Association impairment scale; CCl: Charlson Comorbidity Index; CRP: c reaction protein; ESR: erythrocyte sedimentation rate; TB: tuberculosis; UTI: urinary tract infection; VAS: Visual Analogue Scale; VP: vertebroplasty; WBC: white blood cell

\section{Acknowledgements}

We thank Mrs. Julie Huang, who is an expert in English and helped us to edit the manuscript.

Funding

This article did not receive any funding.

\section{Availability of data and materials}

All the necessary information is contained in the manuscript. The datasets used and/or analyzed during the current study are available from the corresponding author on reasonable request.

\section{Authors' contributions}

LC designed the study and wrote the manuscript. LPL and CLH collected the data. NCC participated in revising the manuscript. All authors read and approved the final manuscript.

\section{Ethics approval and consent to participate}

This study was performed after obtaining approval from the institutional review board of Chang Gung Memorial Hospital (No. 103-4219B). All participates were received and signed informed consent.

\section{Consent for publication}

Not applicable.

\section{Competing interests}

The authors have declared that there are no competing interests.

\section{Publisher's Note}

Springer Nature remains neutral with regard to jurisdictional claims in published maps and institutional affiliations.

Received: 14 June 2018 Accepted: 31 October 2018

Published online: 12 November 2018

\section{References}

1. Galibert P, Deramond H, Rosat P, Le Gars D. Preliminary note on the treatment of vertebral angioma by percutaneous acrylic vertebroplasty. Neurochirurgie. 1987;33:166-8.

2. Al-Nakshabandi NA. Percutaneous vertebroplasty complications. Ann Saudi Med. 2011;31:294-7.

3. Cortet B, Cotten A, Boutry N, Dewatre F, Flipo RM, Duquesnoy B, Chastanet $P$, Delcambre B. Percutaneous vertebroplasty in patients with osteolytic metastases or multiple myeloma. Rev Rhum Engl Ed. 1997:64:177-83

4. Abdelrahman H, Siam AE, Shawky A, Ezzati A, Boehm H. Infection after vertebroplasty or kyphoplasty. A series of nine cases and review of literature. Spine J. 2013;13:1809-17.

5. Ge CY, He LM, Zheng YH, Liu TJ, Guo H, He BR, Qian LX, Zhao YT, Yang JS, Hao DJ. Tuberculous spondylitis following Kyphoplasty. Medicine. 2016;95:e2940.

6. Zou MX, Wang XB, Li J, Lv GH, Deng Y-W. Spinal tuberculosis of the lumbar spine after percutaneous vertebral augmentation (vertebroplasty or kyphoplasty). Spine J. 2015;15:e1-6.

7. Kang JH, Kim H-S, Kim SW. Tuberculous spondylitis after percutaneous Vertebroplasty: misdiagnosis or complication? Korean J Spine. 2013;10:97-100.

8. Kim HJ, Shin DA, Cho KG, Chung SS. Late onset tuberculous spondylitis following Kyphoplasty: a case report and review of the literature. Korean Spine. 2012;9:28-31.

9. Ivo R, Sobottke R, Seifert H, Ortmann M, Eysel P. Tuberculous spondylitis and paravertebral abscess formation after kyphoplasty: a case report. Spine. 2010;35:E559-63.

10. Bouvresse S, Chiras J, Bricaire F, Bossi P. Pott's disease occurring after percutaneous vertebroplasty: an unusual illustration of the principle of locus minoris resistentiae. J Infect. 2006;53:e251-3. 
11. Charlson ME, Pompei P, Ales KL, Mackenzie CR. A new method of classifying prognostic comorbidity in longitudinal studies: development and validation. J Chronic Dis. 1987;40:373-83.

12. Anselmetti GC, Marcia S, Saba L, Muto M, Bonaldi G, Carpeggiani P, Marini S, Manca A, Masala S. Percutaneous vertebroplasty: multi-centric results from EVEREST experience in large cohort of patients. Eur J Radiol. 2012;81:4083-6.

13. Robinson Y, Tschöke SK, Stahel PF, Kayser R, Heyde CE. Complications and safety aspects of kyphoplasty for osteoporotic vertebral fractures: a prospective follow-up study in 102 consecutive patients. Patient Saf Surg. 2008;2:2.

14. Yu SW, Chen WJ, Lin WC, Chen YJ, Tu YK. Serious pyogenic spondylitis following vertebroplasty — a case report. Spine. 2004;29:E209-11.

15. Walker DH, Mummaneni P, Rodts GE Jr. Infected vertebroplasty. Report of two cases and review of the literature. Neurosurg Focus. 2004;17:E6.

16. Lee MJ, Dumonski M, Cahill P, Stanley T, Park D, Singh K. Percutaneous treatment of vertebral compression fractures: a meta-analysis of complications. Spine. 2009;34:1228-32.

17. Syed MI, Avutu B, Shaikh A, Sparks H, Mohammed MI, Morar K. Vertebral osteomyelitis following vertebroplasty: is acne a potential contraindication and are prophylactic antibiotics mandatory prior to vertebroplasty? Pain Physician. 2009;12:E285-90.

18. Clark JJC, Abildgaard JT, Backes J, Hawkins RJ. Preventing infection in shoulder surgery. J Shoulder Elb Surg. 2018;27:1333.

19. Zeller VA, Letembet VA, Meyssonnier VA, Heym B, Ziza JM, Marmor SD. Cutibacterium (Formerly Propionibacterium) avidum: A Rare but Avid Agent of Prosthetic Hip Infection. J Arthroplast 2018 33:2246

20. Yuan Y, Chen Y, Zhou Z, Jiao Y, Li C, Zheng Y, Lin Y, Xiao J, Chen Z, Cao P. Association between chronic inflammation and latent infection of Propionibacterium acnes in non-pyogenic degenerated intervertebral discs: a pilot study. Eur Spine J. 2017. https://doi.org/10.1007/s00586-017-5363-5 [Epub ahead of print].

21. Kim CJ, Song KH, Jeon JH, Park WB, Park SW, Kim HB, Oh MD, Choe KW, Kim NJ. A comparative study of pyogenic and tuberculous spondylodiscitis. Spine. 2010;35:E1096-100.

22. Chen LH, Yang SC, Niu CC, Lai PL, Chen WJ. Percutaneous drainage followed by antibiotic-impregnated cement vertebroplasty for pyogenic vertebral osteomyelitis: a case report. J Trauma. 2008:64:E8-11.

23. Söyüncü $Y$, Ozdemir H, Söyüncü S, Bigat $Z$, Gür S. Posterior spinal epidural abscess: an unusual complication of vertebroplasty. Joint Bone Spine. 2006;73:753-5.

24. Mummaneni PV, Walker DH, Mizuno J, Rodts GE. Infected vertebroplasty requiring 360 degrees spinal reconstruction: long-term follow-up review. Report of two cases. J Neurosurg Spine. 2006;5:86-9.

25. Shin JH, Ha KY, Kim KW, Lee JS, Joo MW. Surgical treatment for delayed pyogenic spondylitis after percutaneous vertebroplasty and kyphoplasty. Report of 4 cases. J Neurosurg Spine. 2008;9:265-72.

26. Park JW, Park SM, Lee HJ, Lee CK, Chang BS, Kim H. Infection following percutaneous vertebral augmentation with polymethylmethacrylate. Arch Osteoporos. 2018;13(1):47. https://doi.org/10.1007/s11657-018-0468-y.

27. Chen YJ, Chen HY, Hsu HC. Re: Infection after vertebroplasty or kyphoplasty. A series of nine cases and review of literature. Spine J 13:1809-17. Spine J. 2014;14:1366. https://doi.org/10.1016/j.spinee.2014.01.057.

\section{Ready to submit your research? Choose BMC and benefit from:}

- fast, convenient online submission

- thorough peer review by experienced researchers in your field

- rapid publication on acceptance

- support for research data, including large and complex data types

- gold Open Access which fosters wider collaboration and increased citations

- maximum visibility for your research: over $100 \mathrm{M}$ website views per year

At $\mathrm{BMC}$, research is always in progress.

Learn more biomedcentral.com/submissions 